\title{
Gestão documental da informação jurídica
}

\section{Ana Cláudia Carvalho de Miranda}

Mestranda em Administração pela UFRN. Especialista em Gestão da Qualidade Total pela UFRN. Especialista em Gestão Estratégica de Pessoas pela FACEX. Bacharel em Biblioteconomia pela UFC.Chefe da Biblioteca do Tribunal de Justiça do Estado do Rio Grande do Norte

Ticiano Maciel D'Amore,

Professor da Escola de Música da UFRN. Mestre em Administração pela UFRN.Doutorando em Administração pela UFRN

Virginia Bentes Pinto

Professora do Departamento de Ciências da Informação da Universidade Federal do Ceará. Doutora em Ciências da Informação e da Comunicação - Université Sténdhal-Grenoble-3França. Mestre em Ciência da Informação pela UFMG

Este artigo apresenta uma nova performance da gestão documental, voltada para o desenvolvimento das coleções no âmbito da informação jurídica, estabelecendo critérios de qualidade para os processos de seleção, aquisição e avaliação das informações. Para esse propósito, é feita uma avaliação das várias dimensões que permeiam a gestão documental da informação jurídica como um todo. A rapidez com que a informação jurídica se inova torna a literatura (ainda que recente) ultrapassada e obsoleta, ocasionando, assim, uma maior dificuldade das bibliotecas permanecerem com suas publicações sempre atualizadas. Por isso, é preciso que sejam elaborados mecanismos de controle e que seja efetuado um bom desenvolvimento dos serviços prestados pelas mesmas. Esses mecanismos são criados por meio da política de desenvolvimento de coleções, pois, quando bem fundamentada, assegura o bibliotecário na tomada de decisões, tanto em relação ao processo de seleção, aquisição e descarte do acervo, como na sustentação da qualidade na atualização da coleção. O processo de desenvolvimento da coleção é visto sob o viés da abordagem sistêmica das organizações. 
Palavras-chave: Gestão documental; Política de desenvolvimento de coleções; Informação jurídica; Biblioteca jurídica.

\section{Document management of legal notice}

This paper presents a new performance document management focused on thedevelopment of the collections within the juridical information, estabilishing quality criteria for process selection, acquisition and evaluation of information. For this purpose, an assessment is made of the various dimensions that permeate the document management of legal material as a whole. The speed of innovation of legal material becomes even recent literature, overshot and obsolet, causing thus a greater difficulty of remain libraries with up to date. So they need to be developed control mechanisms, and is made a good developement of the services provided by them. These mechanisms are created through the collection development of the services provided by them. These mechanisms are created through the collection development policy, because when the library nsures well-founded decisionmaking, both in relation to the process of selection, acquisition and disposal of the collection. The process of collection development is seenin the view of the Systemic approach of organizations.

Keywords: Document management; Collection development policy; Legal information; Law library.

Recebido em 19.12.2012 Aceito em 30.04.2013

\section{Introdução}

A sociedade atual é marcada pelo fluxo constante e elevado de informações, que cria um ambiente favorável para a produção de novos conhecimentos e avanços tecnológicos, no qual a informação tem, a cada dia, maior relevância no cenário das decisões, qualquer que seja sua natureza: política, jurídica, financeira, etc. Tal fato tem levado a vários questionamentos sobre a fidedignidade do conteúdo produzido em períodos determinados.

No que tange à formação de acervos de biblioteca, é exigido dos bibliotecários uma atuação diferenciada, em razão do descontrole causado pela "poluição de informações", sendo preciso realizar uma filtragem 
adequada das mesmas, obedecendo a padrões estabelecidos de seleção e qualidade, que garantam a disponibilidade de obras confiáveis nos diversos suportes informacionais.

A gestão da coleção é fator fundamental à plena consecução dos objetivos das bibliotecas. A formação, o desenvolvimento e a organização do acervo devem ser encarados como um processo permanente, no qual as atividades de seleção, aquisição e avaliação de materiais permaneçam em contínua sintonia com as necessidades de informação da comunidade de usuários. No caso específico deste artigo, consideramos que as bibliotecas jurídicas devem atender às necessidades de informação das organizações ou empresas as quais se encontram subordinadas, visando amparar a tomada de decisão. Portanto, trata-se de um artigo de revisão, apoiado não apenas na literatura das Áreas de Biblioteconomia e Ciência da Informação, mas, também naquelas das Ciências Administrativas concernentes a gestão, para, em seguida, trazer para a gestão documental da informação no contexto jurídico.

\section{Informação jurídica}

Não é novidade afirmarmos de que, na contemporaneidade da segunda metade do século $X X$ e neste século XXI, a informação é vista como um instrumento poderoso de transformação do ser humano, encontrando-se presente em seu cotidiano, permeando suas relações sociais, econômicas e culturais e, adquirindo, nesse sentido, um caráter decisivo para o alcance dos objetivos que se propõe atingir e criando com ela um vínculo de dependência para sua melhor adaptação ao meio em que vive. Nesse contexto, quando utilizada sabiamente, a informação contribui como instrumento formador da consciência crítica do indivíduo, podendo levá-lo à conquista do sucesso intelectual e profissional ou, em caso contrário, ao fracasso e à própria estagnação.

São vários os tipos e natureza da informação, ressaltando-se, entre eles, a informação jurídica, cuja literatura especializada dá a conhecer alguns conceitos e definições. Para Alonso (1998 apud Rezende 2004, p. 175),

[...] sob o aspecto genérico, pode ser conceituada como qualquer dado ou fato, extraído de toda e qualquer forma de conhecimento da área jurídica, obtido por todo e qualquer meio disponibilizado e que pode ser usado, transferido ou comunicado sem a preocupação de estar integrado a um contexto. É um dado ou qualquer elemento identificado em sua forma bruta que por si só não conduz a uma compreensão de determinado fato ou situação.

Informação jurídica, sob o aspecto de documentação organizada, é o produto da análise dos dados existentes em toda e qualquer forma de conhecimentos obtidos na área jurídica, devidamente registrados, classificados, organizados, relacionados e interpretados dentro de um contexto para 
transmitir conhecimento e permitir a tomada de decisão de forma otimizada. A disponibilização desses dados, devidamente trabalhados, é feita através de meios manuais/mecânicos/magnéticos aos interessados.

Logo, embora seja um tipo bem particular de informação, em realidade, sua função maior é contribuir para as tomadas de decisões relativas, não apenas relativas ao exercício da cidadania, mas, também, como prerrogativa de garantia dos direitos individuais, pois todo cidadão precisa estar a par dos seus direitos. Neste, Passos (1994, p. 363) esclarece que esse tipo de informação diz respeito a:

toda unidade de conhecimento humano que tem a finalidade de embasar manifestações de pensamento de jurisconsultos, advogados, legisladores, desembargadores, juízes e todos aqueles que lidam com a matéria jurídica, quando procuram estudar (do ponto de vista legal) ou regulamentar situações, relações e comportamentos humanos, ou ainda quando interpretam e aplicam dispositivos legais.

A informação jurídica é originada fundamentalmente por um tripé informacional distinto: Legislação, Doutrina e Jurisprudência. Legislação é o conjunto normativo que regula a convivência social, elaborada pelo Poder Legislativo dos Municípios, Estados e União; a Doutrina é o conjunto de princípios expostos nas obras de direito, em que se firmam teorias ou se fazem interpretações sobre a ciência jurídica; e a Jurisprudência é a sábia interpretação e aplicação das leis a todos os casos concretos que se submetem a julgamento da justiça, que produz sentenças, no primeiro grau, ou acórdãos e súmulas, nos Tribunais.

A recuperação inadequada da Legislação e da Jurisprudência tanto provoca insatisfação em seus usuários como pode gerar danos, especialmente aos juristas, englobando todos os que se utilizam dela. Quanto à Doutrina, esta não exige uma recuperação exaustiva, mas pelo menos razoável, já que um grande volume de informações necessita ser atualizado, ainda que isso ocorra em pequenos intervalos de tempo através do lançamento de uma nova edição.

O setor de informação jurídica, talvez, seja o maior produtor de documentos no Brasil. É o que destaca Cunha (2010), justificando essa afirmação ao relatar o imenso universo de advogados brasileiros, o número de cursos graduação em Direito e, também, a rápida obsolescência desse tipo de informação, em decorrência da constante desatualização da legislação, alterando automaticamente o conjunto sistemático do Direito.

Nesse contexto, Barros (2004) ressalta a explosão de informações jurídicas em razão da grande quantidade de documentos expedidos pelas autoridades legislativas, judiciárias e administrativas, como, também, da 
complexidade das especificações da área. Por ser elemento imprescindível, a informação jurídica necessita ser devidamente sistematizada em seu âmbito de circulação para que os objetivos jurídicos sejam alcançados.

As bibliotecas tradicionais têm sido responsáveis pela organização, pelo tratamento e pela disseminação da informação. Em se tratando de dados jurídicos, são as bibliotecas jurídicas que assumem o importante papel de aglutinadoras de conhecimento para promoção de efeitos legais na relação entre unidade jurídica e sociedade. Nesse sentido, as bibliotecas jurídicas objetivam disseminar a informação jurídica, especialmente na esfera de suas instituições mantenedoras, com o intuito de subsidiar as decisões processuais em fluxo, como, também, auxiliar a todos os juristas na aplicação da justiça e até mesmo criar pensamento jurídico.

As bibliotecas jurídicas são provenientes de órgãos governamentais, universidades ou escritórios de advocacia e atuam como principal veículo disseminador desse tipo de informação. À medida que tornam acessíveis doutrinas, leis, decretos, pareceres, sentenças, elas contribuem no exercício dos magistrados, legisladores e membros do mistério público, que se utilizam dos estudos da informação jurídica para interpretar e aplicar os dispositivos legais em suas decisões.

Barros (2004, p. 205-206) destaca a informação jurídica como sendo a base essencial ao ofício dos juristas, legisladores, advogados, estudantes e profissionais de Direito, consultores jurídicos, juízes, desembargadores, ministros, procuradores, membros do Ministério Público e outros profissionais de carreira.

A demanda da informação jurídica tem crescido bastante, em consequência do público interessado em prestar concurso, não apenas destinado à carreira jurídica, mas, também, a outras áreas, cujo programa abrange conteúdo de diferentes ramos do campo jurídico. Com base nessa procura e por meio de um acompanhamento contínuo, pode-se obter suporte para elaboração de um diagnóstico que deve descrever o perfil da clientela, ou seja, seus costumes de leitura, sua frequência à biblioteca, seus novos interesses informacionais, suas formas e fontes de busca e tudo o que for importante ao sistema identificar.

Os acervos das bibliotecas jurídicas devem estar organizados, visando à satisfação de necessidades informacionais específicas desse público. Nesses termos, as mesmas devem possuir um bom planejamento no desenvolvimento de suas coleções, assim como mecanismos de coordenação e controle bem definidos.

\section{Desenvolvimento de coleções sob uma abordagem sistêmica}

Ao longo do tempo e devido a grande produção de conhecimentos registrados, as bibliotecas desenvolveram metodologias e políticas para a o desenvolvimento de coleções, que viessem contribuir tanto para a 
formação de seus acervos como também para o desbaste e descarte daqueles documentos considerados, pelos critérios estabelecidos, como não fundamentais em suas coleções. Essas metodologias e políticas vêm ao encontro daquelas relativas a avaliação, coordenação e controle, oriundas das Ciências Administrativas, principalmente.

No entendimento de Mintzberg (1995), pode-se coordenar e controlar através da padronização dos processos - os passos para a execução do trabalho, nesse caso, são previstos e especificados. No âmbito da gestão bibliotecária, tal mecanismo se refletiria no desenvolvimento de coleções. Desenvolver coleções implica sistematizar e criar procedimentos para seleção, aquisição, avaliação e desbastamento do acervo.

De acordo com Bertalanffy (1976), a teoria geral dos sistemas descreve as organizações como sistemas com algumas características próprias, cujos modelos podem ser aplicados em diversas áreas do conhecimento. Para Park (1987, p. 146), um sistema é "um complexo de elementos em interação de natureza ordenada e não fortuita". Ressalta, ainda, que, por seu caráter interdisciplinar, pode ser aplicada em diversos ramos da pesquisa. As duas características obrigatórias para uma visão sistêmica são o funcionalismo e o holismo. A primeira definição aborda as partes do sistema e seu papel a desempenhar no sistema mais amplo. 0 holismo, por sua vez, é a "concepção de que todos os sistemas se compõem de subsistemas e seus elementos estão inter-relacionados" (PARK, 1987, p. 146).

A biblioteca, como qualquer organização, é um sistema aberto, pois realiza intercâmbio com o meio externo. Suas relações com o meio (tanto fornecedores quanto clientes) são fundamentais para o estabelecimento de metas e ações futuras. O desenvolvimento de uma coleção, sob uma abordagem sistêmica, deve analisar cada etapa de seu processo tanto sobre sua utilidade para o resultado final (funcionalismo) quanto sobre seu papel para o processo como um todo (holismo).

Para compactuar com a abordagem sistêmica, as coleções precisam evoluir harmoniosamente em todas as áreas do acervo, evitando seu crescimento desordenado, sem metas ou objetivos definidos. Entretanto, Figueiredo (1999) recomenda que a coleção seja equilibrada, tomando por base os relatórios estatísticos em coleta regular: onde for constatado maior uso, a coleção deverá ser fortalecida; em caso contrário, a coleção poderá ser mais fraca, e para área de assunto sem demanda, não é preciso manter coleção alguma. O importante é ter conhecimento de outras bibliotecas, na quais os usuários possam ser encaminhados e atinjam a plena satisfação de suas necessidades informacionais.

É através do viés sistêmico que a gestão da documentação jurídica deve estar totalmente sintonizada com os objetivos de cada tipo de biblioteca. Os usuários também desempenham relevante papel nessa atividade. Ao se iniciar o processo de desenvolvimento de coleções, devemos primeiramente realizar um estudo da comunidade a que se destina a biblioteca, para posteriormente realizar uma análise que 
favoreça a caracterização do perfil e das necessidades informacionais, baseados em técnicas, como a pesquisa de campo, utilizando questionários e/ou entrevistas.

Depois de concluído o diagnóstico, serão tomadas algumas decisões quanto às políticas que conduzirão o processo de desenvolvimento de coleções, dentre as quais Maciel (2000, p. 18) destaca:

- indicação do responsável pelo processo de seleção - que poderá ser o bibliotecário ou uma comissão constituída pelo bibliotecário e outros membros nomeados pelo dirigente da instituição mantenedora;

- determinação das áreas que farão parte do acervo;

- recomendação do tipo de documento que irá compor o acervo, independente do seu suporte físico;

- estabelecimento dos critérios e prioridades que nortearão toda operação, incluindo as decisões nas etapas de seleção, aquisição e também o desbastamento da coleção, indicando o que deve ser transferido para depósitos especiais ou mesmo ser descartados;

- estabelecimento de diretrizes para a avaliação das coleções, até mesmo com indicação da periodicidade com que deverá ser realizada;

- definição da quantidade de exemplares por título, especialmente para as coleções de uso corrente;

- estabelecimento de diretrizes para a preservação e conservação do acervo, contendo informações sobre as condições ambientais ideais para cada tipo de documento; e

- determinação de prazos para revisão das políticas.

Finalizada a elaboração das políticas, materializa-se o documento administrativo, oficializando-o perante os administradores da instituição e denominando-o "Política de desenvolvimento de coleções", o qual deverá ser revisto a cada 2 (dois) anos pela Comissão de Biblioteca, com o objetivo de garantir o acesso e a adequação à comunidade jurídica e aos objetivos da instituição, por meio da produção e adoção de parâmetros sólidos de apoio ao processo como um todo. Em outras palavras, a política de desenvolvimento de coleções é um documento que estabelece critérios para garantir a qualidade e a credibilidade da coleção, no tocante à tomada de decisões relacionadas à incorporação ou à retirada definitiva de materiais pertencentes ao acervo.

\subsection{Política de desenvolvimento de coleções}

O desenvolvimento do acervo deve ser fundamentado num planejamento norteador que sustente sua continuidade e adequação 
necessária, no qual sejam determinadas políticas e diretrizes para seleção e aquisição de materiais informacionais.

A Política de Desenvolvimento de Coleções é um documento que aborda normas e diretrizes para auxiliar a decisão de incorporação ou rejeição de um determinado título à formação do acervo. Ela registra os critérios para seleção de todos os tipos de materiais, nas diversas formas de aquisição, além de orientar na indicação do material que deve ser descartado ou remanejado.

A política funcionará, segundo Vergueiro (1989), como parâmetro que contribuirá na tomada de decisão dos bibliotecários em relação à escolha do material a ser incorporado ao acervo e à própria administração dos recursos informacionais. Ela fornecerá uma exposição do estado geral da coleção, demonstrando o método adequado para alcançar objetivos e dar subsídios para os bibliotecários argumentarem com as autoridades superiores sobre a liberação de novas aquisições ou sobre recusas incoerentes.

Quanto à elaboração da política, Vergueiro (1989) destaca que é imprescindível ter alguns dados essenciais para apreciação, tais como: o estado atual da coleção (quais áreas jurídicas encontram-se inadequadas, necessitando de novas aquisições e quais áreas encontram-se eficientes para atender a demanda) e as necessidades informacionais da comunidade a ser servida.

Para preparação da política, é preciso estabelecer os objetivos para possibilitar um melhor direcionamento na gestão do acervo, visando:

a) garantir um crescimento racional e equilibrado do acervo na área jurídica de forma qualitativa e quantitativa;

b)reconhecer os elementos adequados à formação e continuidade da coleção;

c)definir os critérios para duplicação de títulos;

d)propor as prioridades de aquisição de material;

e)conhecer as necessidades dos usuários, através da análise de uso das coleções e sua atualidade;

f)manter atualizado quanto ao surgimento dos novos suportes de informação, não se limitando apenas ao suporte em papel; e

g)estabelecer diretrizes para o descarte e reposição de material.

Na política de desenvolvimento de coleções, uma das etapas mais importantes é o processo de seleção, pois através dele são estabelecidos os critérios que comprovam a qualidade e o ajustamento para atender, a contento, as reais necessidades dos usuários.

\subsubsection{Processo de seleção da coleção}


Para Park (1987), um sistema tem inputs e outputs. Os inputs são as entradas que farão parte dos sistemas e subsistemas, serão processados e se transformarão em outputs, em forma de serviços, produtos e valores econômicos, lançados no meio externo. Tais inputs representam, nesta pesquisa, a coleção que será integrada ao acervo da biblioteca e o processo de seleção dessa coleção merece destaque, pois favorece o desenvolvimento de medidas estratégicas, com a finalidade de propor critérios que busquem facilitar a tomada de decisão na formação e desenvolvimento da coleção, em sintonia com os objetivos de cada instituição na qual a biblioteca esteja inserida.

Quanto à seleção da informação jurídica, Miranda (2004, p. 144) destaca ser, cada vez mais criteriosa, por várias circunstâncias:

-avanço nas alterações das leis, emendas constitucionais, decretos, jurisprudências, etc., causando uma crescente obsolescência das publicações;

- intensificação da interdisciplinaridade (vinculando áreas, antes isoladas, com o Direito; exemplo: o Biodireito, Direito Ambiental, etc. );

- diversidade no formato (relatórios, artigos de periódicos, anais de congressos, livros e outros) e no suporte (impresso, eletrônico, digital e outros).

O bibliotecário jurídico, para acompanhar essa evolução, precisa realizar uma contínua exploração na literatura jurídica, veículo do Direito, pois esta, a todo instante, atualiza-se frentes às novas realidades sociais detectadas pela ciência do dever ser. Contudo, é necessário averiguar uma possível mudança significativa na área jurídica, objeto da compra, pois se corre o risco da aquisição de documentos com valor puramente histórico, sem nenhum valor prático imediato.

Essa análise reporta à afirmação de Campos (2002), referente à $5^{a}$. Lei de Ranganathan: "a biblioteca é uma organização em crescimento", tendo em vista que a produção do conhecimento é uma ação permanente. Esse processo não é fácil de realizar, todavia, entre os milhões de documentos informacionais que são lançados no mercado editorial.

A política de seleção deve ser flexível, a fim de facilitar quaisquer atualizações necessárias, de maneira a viabilizar as decisões quanto à incorporação ou não dos materiais previamente selecionados, com base na análise do uso, qualidade e valor.

Muller (2000, p. 24) apresenta, ainda, que "a política de seleção do acervo deve ser muito bem planejada e suplementada por esquemas de cooperação com outras bibliotecas". Temos, como exemplo, a implementação de grupos de informação jurídica, existentes em vários estados brasileiros, em que as bibliotecas jurídicas compartilham, cooperam, apoiam e promovem as informações entre si, para atender à demanda da clientela que ultrapassa a possibilidade da coleção local. 
O processo de seleção da informação jurídica deve estar diretamente relacionado com os objetivos da instituição mantenedora e o interesse do usuário individual inserido dentro de uma cultura organizacional, com necessidades diversificadas e demandas a serem supridas. É importante analisar, na seleção, as indicações e as sugestões dos usuários, bem como suas observações de quais áreas jurídicas encontram-se desatualizadas e escassas. Esse procedimento na seleção é indispensável, visto que de nada valeria ter um acervo imenso, porém inadequado aos clientes, pois, sem eles, a biblioteca não passaria de um depósito de documentos e deixaria de realizar seu papel de organizar, processar e disseminar as informações, objetivando sua difusão e criando meios para a proliferação do saber para futuras gerações.

\subsubsection{Processo de aquisição}

A aquisição determina a concretização das decisões tomadas no processo de seleção, ou seja, é o procedimento destinado à incorporação dos documentos à coleção.

A agregação de materiais informacionais à coleção da biblioteca pode ocorrer através de três modalidades: compra, doação e permuta. A finalização desse processo por compra é uma tarefa minuciosa por parte do profissional encarregado de sua devida concretização e correspondência perfeita com o material selecionado, fato que não ocorre no que diz respeito à doação e à permuta, nas quais não se requer tanto empenho do profissional. Apesar disso, todo material originário dessas modalidades deve ser analisado antes de ser adicionado ao acervo, para não criar uma coleção imensa, porém, fora da realidade e dos interesses a que se destina.

$\mathrm{Na}$ aquisição por compra, as atividades são bastante complexas, como apresentado no relato abaixo:

à aquisição caberá o trabalho minucioso de identificação, localização dos itens e sua posterior obtenção para o acervo, qualquer que seja a maneira de tornar isto possível. E não é uma tarefa assim tão automática, pois, infelizmente para os profissionais, os títulos selecionados não se encontram acenando para eles ao dobrar da esquina, a gritar "olha eu aqui, olha eu aqui" e quase implorando para serem adquiridos. Muitas vezes, realizar um trabalho de aquisição assemelha-se a procurar uma agulha em palheiro, tantas são as possibilidades e dificuldades existentes. É uma atividade que exige perseverança e atenção a detalhes, de maneira a evitar um descompasso entre o que foi escolhido primeiramente para aquisição e aquilo que chega às mãos do usuário. (ANDRADE, 1996, p. 6).

O planejamento da compra deve ser previamente estabelecido mediante análise dos recursos financeiros, para garantir uma visão concreta do que se pode obter. Andrade (1996) salienta que, na prática, 
o orçamento previsto para aquisição de materiais nem sempre corresponde aos recursos liberados, ocasionando que nem todas as necessidades consideradas prioritárias serão atendidas.

O obstáculo no processo de aquisição, enfrentado por todas as bibliotecas, é a escassez financeira de recursos, que leva forçosamente o bibliotecário a determinar o que de imprescindível irá ser adquirido e desprezar os documentos não prioritários ou não emergenciais. Esse cenário não é diferente da realidade nas bibliotecas jurídicas. Como exemplo, ao invés de se comprar um título específico (tutela antecipada), será efetuada a aquisição de um genérico (curso completo de processo civil), que aborda tanto o assunto específico quantos outros igualmente importantes.

Martinez e Jarrilo (1989) sugerem o contato direto entre gerentes de diferentes departamentos, dividindo questões, decisões e problemas; e equipes temporárias ou permanentes, comitês e departamentos de integração. Tendo essa proposta como base, uma solução para melhor driblar a falta de recursos financeiros é a aquisição compartilhada, decisão de várias bibliotecas em estabelecer uma rede de aquisição para participarem de uma troca entre si de informação, pois, quando uma adquire, comunica às demais, não sendo necessário adquiri-lo e, principalmente, no que diz respeito às assinaturas de periódicos e bases de dados, em que os conteúdos são encaminhados para a biblioteca solicitante.

\subsubsection{Avaliação da coleção}

Avaliação é o processo empregado para determinar a importância e a adequação do acervo com os objetivos da Biblioteca e da instituição, possibilitando traçar parâmetros quanto à aquisição, à acessibilidade e ao descarte, sendo, portanto, imprescindível ao bibliotecário jurídico ter conhecimento básico sobre a obsolescência na área.

Para Park (1987, p. 149), o mecanismo de feedback da abordagem sistêmica "remete as suas entradas, de forma a controlar o funcionamento do sistema". No caso da avaliação de um acervo, Lancaster (1996, p. 20) recomenda, antes de começar o processo de avaliação do acervo, a realização de uma análise baseada em:

o que a biblioteca deveria possuir e não possui, e o que possui, mas não deveria possuir, tendo em vista fatores de qualidade e adequação da literatura publicada, sua observância, as mudanças de interesses dos usuários, e a necessidade de otimizar o uso de recursos financeiros limitados.

Segundo Dias e Peris (2003), a avaliação do acervo é mostrada como a verificação da política de desenvolvimento de coleção, mediante o uso adequado de técnicas e métodos, auxiliando, também, no desbastamento da coleção, ou seja, no deslocamento ou exclusão de documento. 
As técnicas empregadas para avaliar a coleção são quantitativas (tamanho e crescimento) e qualitativas (julgamento por especialistas, análise do uso real). Após comparação dos resultados, fruto das análises, assegura-se o alcance dos objetivos da avaliação da coleção, como, também, se cria um melhor suporte para a qualidade da política de desenvolvimento de coleções.

A avaliação qualitativa, baseada nos julgamentos por especialistas em um assunto, pode trazer alguns problemas, conforme destaca Lancaster (1996): o especialista talvez não seja completamente imparcial, como, também, não está familiarizado com o perfil da comunidade que a biblioteca atende.

A análise comparativa - entre o que é comprado e o uso subsequente - é apresentada por Figueiredo (1991), como um meio para realizar a avaliação. Essa análise favorece a melhora da seleção, quer pela identificação dos tipos de material com pouca chance de ser utilizado, quer pela alteração no processo de seleção que acarreta em compra de materiais desnecessários para a clientela.

Alguns critérios para avaliação da gestão documental da coleção jurídica são sugeridos por Miranda (2004, p. 148):

a) Análise distribucional do percentual do acervo por área jurídica- é executada por meio da verificação das estatísticas de uso do material que consentirá na determinação das áreas que devem ter a sua coleção inovada (seja em exemplares, títulos, material em português, etc.) e quais as áreas de pesquisa encontram-se desprovidas de materiais bibliográficos e especiais que necessitam de providências. Em contrapartida, se for confirmada a subutilização dos recursos bibliográficos em alguma área, a biblioteca deverá averiguar a causa do problema, podendo ser a falta de qualidade do material existente, desatualização, falha de interesse, desconhecimento da existência da obra, etc.

b) Satisfação dos clientes - é um parâmetro seguro para se avaliar as coleções e, portanto, através da mesma poder-se-á: verificar se a coleção atende os interesses dos usuários; determinar os tipos e níveis de necessidade em relação às coleções e as mudanças de interesse por parte da clientela.

c) Estudo paralelo das coleções com listas, catálogos e bibliografias recomendadas - o emprego deste método incide na comparação do acervo com listas, bibliografias recomendadas e/ou adotadas, para examinar os itens não existentes na biblioteca e quais devem ser adquiridos.

d) Custo/efetividade - capacidade alcançar um objetivo por um custo acessível.

\section{Considerações finais}


Muitas são as barreiras a serem enfrentadas ao se comentar a intensidade com que se renova a informação jurídica e é imprescindível ao bibliotecário jurídico manter-se atualizado na busca pelo contínuo acompanhamento das mais recentes mudanças na legislação, evitando-se, dessa forma, a aquisição de publicações já ultrapassadas, bem como o fornecimento de informações em desacordo com a legislação em vigor.

Diante de tais constatações, pode-se admitir que o papel da gestão da biblioteca jurídica seja difundir a informação jurídica, principalmente no âmbito das instituições das quais fazem parte, com o intuito de amparar as decisões nos processos judiciais em curso. Desse modo, auxilia os juristas na aplicação da justiça, levando-Ihes o Direito em seu estado bruto para que possa ser lapidado, através das regras de interpretação, achando-se, ao final, a norma a ser aplicada na solução do caso, contribuindo para pacificação da sociedade. Para tal, é preciso ter-se executado perfeitamente cada fase do desenvolvimento de coleções, a fim de possuir todos os assuntos relevantes à demanda. Dessa forma e de acordo com a literatura abordada, o funcionalismo e o holismo da abordagem sistêmica vão garantir que as etapas para a consecução do processo tenham uma relação de dependência e função que contribui significativamente para o resultado final.

O volume destinado aos títulos para cada área jurídica deve continuar a ser adequado aos interesses da instituição mantenedora e da comunidade. Tendo em vista o longo caminho a ser percorrido, é recomendado elaborar uma política de desenvolvimento de coleções que englobe os objetivos da instituição mantenedora, com a finalidade de subsidiar a gestão documental, facilitando a tomada de decisão no processo de seleção, considerando todos os fatores relevantes aos interesses da comunidade, bem como avaliando a coleção periodicamente para preservar a qualidade e a idoneidade do acervo.

Essa visão, considerando o nível de complexidade e a escassez nos recursos financeiros nas instituições públicas, propicia a necessidade de eleger critérios de seleção que auxiliem na adequação das informações aos interesses da comunidade jurídica, perante o processo de aquisição dos documentos a serem incluídos na coleção. Busca-se, com isso, alcançar melhores resultados para satisfação da clientela.

Assim, a qualidade na gestão documental está voltada para a aplicação de uma política de desenvolvimento de coleções, condicionada à flexibilidade para alterar ou ajustar o material jurídico disponível sempre que for comprovado que a biblioteca não esteja atendendo às reais necessidades dos seus usuários, procurando, dessa maneira, ajustá-la às atuais demandas informacionais.

\section{Referências}

Alonso (1998 apud Rezende 2004)

ANDRADE, D.; VERGUEIRO, V. Aquisição de materiais de informação. Brasília: Briquet de Lemos, 1996. 
ASHWORTH, Wilfred. Manual de bibliotecas especializadas e serviços informatizados. 2. ed. Lisboa: Fundação Calouste GulbenKian, 1981.

BARRETO, Aldo de Albuquerque. A questão da informação. Disponível em: <http://www.alternex.com.br/ aldoibct/quest/quest.htm>. Acesso em 25 ago. 2003.

BARROS, L. Fontes de informação jurídica. In: PASSOS, E. (Org.). Informação jurídica: teoria e prática. Brasília: Thesaurus, 2004. p. 201225.

BERTALANFFY, L. v. Teoria general de los sistemas: fundamentos, desarrollo, aplicaciones. Ciudad de Mexico: FCE, 1976.

CAMPOS, M. L. de A. As cinco leis da biblioteconomia e o exercício profissional.

em: <http://www.conexario.com/biti/mluiza/index.htm>. Acesso em: 24 abr. 2002.

CUNHA, M. B. da. Manual de fontes de informação. Brasília: Briquet de Lemos, 2010.

CUNHA, Murilo Bastos da; CAVALCANTI, Cordélia Robalinho de Oliveira. Dicionário de Biblioteconomia e Arquivologia. Brasília: Briquet de Lemos, 2008.

DIAS, M. M. K.; PIRES, D. Formação e desenvolvimento de coleções de serviços de informação. São Carlos: EdUFSCar, 2003.

FIGUEIREDO, N. M. de. Metodologias para a promoção do uso da informação: técnicas aplicadas particularmente em bibliotecas universitárias e especializadas. São Paulo: Nobel, 1991.

FIGUeIREDO, N. M. de. Paradignas modernos da Ciência da Informação: em usuários, coleções, referências \& informação. São Paulo: Polis,1999.

GUINCHAT, Claire; MENOU, Michel. Introdução às ciências e técnicas da informação e documentação. Brasília: IBICT, 1994.

LANCASTER, F. W. Avaliação de serviços de bibliotecas. Brasília: Briquet de Lemos, 1996.

LE COADIC, Yves-François. A ciência da informação. Brasília: Briquet de Lemos, 1996.

MACHADO, Maria Teresa Ferlini. Relacionamento biblioteca/usuário: fator relevante no processo de disseminação da informação jurídica. In: CONGRESSO BRASILEIRO DE BIBLIOTECONOMIA E DOCUMENTAÇÃO, 19., 2000, Porto Alegre. Anais... Porto Alegre: PUCRS, 2000. 1 CD.

MACIEL, A. C.; MENDONÇA, M. A. R. Bibliotecas como organizações. Rio de Janeiro: Interciência, 2000.

MARTINEZ, J. I; JARILLO, J. C. The evolution on research on coordination mechanisms in multinational companies. Journal of International Business Studies, 1989. 
MINTZBERG, H. Criando organizações eficazes: estruturas em cinco configurações. São Paulo: Atlas, 1995.

MIRANDA, A. C. C. de. A política de desenvolvimento de coleções no âmbito da informação jurídica. In: PASSOS, E. (Org.). Informação jurídica: teoria e prática. Brasília: Thesaurus, 2004.

MULLER, S. P. M. A ciência, o sistema de comunicação científica e a literatura científica. In: CAMPELO, B. S. (Org.). Fontes de informação para pesquisadores e profissionais. Belo Horizonte: UFMG, 2000.

PARK, Kil H; BONIS, D. F. de; ADUD, M. R. Introdução ao estudo da administração. São Paulo: Pioneira, 1997.

PASSOS, E. Bibliotecário jurídico: seu perfil, seu papel. Disponível em: <http://www.infolegis.com.br/perfilbibjridico.htm>. Acesso em: 26 set. 2002.

PASSOS, Edilenice; Barros, Lucivaldo Vasconcelos. Fontes de informação para pesquisa em Direito. Brasília: Briquet de Lemos, 2009.

PASSOS, E. O controle da informação jurídica no Brasil: a contribuição do Senado Federal. Ciência da informação, Brasília, v. 23, n. 3, p. 363-368, set./dez. 1994.

REZENDE, A. P. de. Pesquisa jurídica em fonte eletrônicas. In: PASSOS, E. (Org.). Informação jurídica: teoria e prática. Brasília: Thesaurus, 2004. p. 173-188.

VERGUEIRO, V. de C. S. Desenvolvimento de coleções. São Paulo: Polis, 1989. (Coleção Palavra-chave, 1 ). 1995.

. Seleção de materiais de informação. Brasília: Briquet de Lemos, 2.ed. Brasília: Briquet de Lemos, 1997. 